\title{
Evaluating Chemotherapy-induced Nausea and Vomiting and Food Intake in Patients With Gynecologic Cancer
}

\author{
HIROAKI KOMATSU ${ }^{1,2}$, TETSURO OISHI ${ }^{1}$, SHINYA SATO ${ }^{1}$, DAIKEN OSAKU ${ }^{1}$, \\ MAYUMI SAWADA ${ }^{1}$, AKIKO KUDOH ${ }^{1}$, MICHIKO NONAKA $^{1}$, SEIYA SATO $^{3}$, \\ MUNEAKI SHIMADA ${ }^{4}$, HIROAKI ITAMOCHI ${ }^{3}$ and TASUKU HARADA ${ }^{1}$

\begin{abstract}
${ }^{1}$ Department of Obstetrics and Gynecology, Tottori University School of Medicine, Yonago, Japan;
${ }^{4}$ Department of Obstetrics and Gynecology, Tohoku University School of Medicine, Sendai, Japan
\end{abstract} \\ ${ }^{2}$ Department of Obstetrics and Gynecology, Japanese Red Cross Yamaguchi Hospital, Yamaguchi, Japan; \\ ${ }^{3}$ Department of Obstetrics and Gynecology, Iwate Medical University School of Medicine, Morioka, Japan;
}

\begin{abstract}
Background/Aim: Treatments for controlling delayed nausea after chemotherapy are inadequate, potentially inciting malnutrition. We sought to determine the incidence of nausea, anorexia, and food intake after chemotherapy. Patients and Methods: Subjects were females with gynecological cancers who underwent chemotherapy between 2008 and 2013. Nausea, anorexia, and food intake in the acute (day 1) and delayed phases (days 2 and 3) were retrospectively evaluated. Results: Subjects included 156 females. Chemotherapies were highly $(H E C ; n=24)$ and moderately emetogenic (MEC; $n=132)$. There were no significant between-group differences for anorexia control during either the acute or the delayed phase and both groups demonstrated significantly worse control of nausea during the delayed phase. In the HEC group, food intake was significantly reduced on days 2 and 3 compared with day 1. Conclusion: Rates of nausea, anorexia, and food intake significantly worsened over time, particularly in the MEC group. Current supportive therapies appear inadequate and should be improved.
\end{abstract}

Chemotherapy-induced nausea and vomiting (CINV), and anorexia are factors that influence treatment compliance in patients who undergo chemotherapy. Although recently developed antiemetics have reduced the occurrence of CINV, it remains a prominent adverse effect of cancer treatment. 5HT3 receptor antagonists are used to address CINV in clinical settings, but carry certain drawbacks. Despite

Correspondence to: Tetsuro Oishi, Department of Obstetrics and Gynecology, Tottori University School of Medicine, 36-1 Nishicho, Yonago, Tottori, 683-5804, Japan. Tel: +81 859386647, Fax: +81 859386649, e-mail: tetsuro@med.tottori-u.ac.jp

Key Words: Chemotherapy, CINV, gynecological cancer. available prophylactic treatments, dietary intake after chemotherapy affects patients' compliance and nutrition. Furthermore, accurate measures of CINV are needed to help prevent occurrence (1).

The American Society of Clinical Oncology (ASCO), National Comprehensive Cancer Network ( $\mathrm{NCCN}$ ) and the Multinational Association of Supportive Care in Cancer (MASCC)/European Society for Medical Oncology (ESMO) have separately published guidelines for prevention of CINV, and supportive therapies that support patients' quality of life (QOL) are used alongside cancer chemotherapy worldwide (24). In 2015, the Japan Society of Clinical Oncology (JSCO) revised its clinical practice guidelines on antiemesis (GL2015) (5) and classified all chemotherapy regimens as highly emetogenic chemotherapy (HEC), moderately emetogenic chemotherapy (MEC), low emetogenic chemotherapy (LEC), and minimal emetogenic risk, according to their likelihood of causing CINV. Appropriate antiemetic treatment selection can now consider emetogenic risk. Recently, combination chemotherapy consisting of paclitaxel and carboplatin (TC) is commonly used as first-line chemotherapy in patients with gynecologic cancers. Although the TC regimen was classified as MEC in the GL2015, the latest guidelines recommended administration of three antiemetic agents for TC, which are the same as HEC.

Vomiting is considered an acute response that occurs within $24 \mathrm{~h}$ after chemotherapy; however, vomiting can also manifest as a delayed response which appears $24 \mathrm{~h}$ or more after chemotherapy, often persisting for 5-7 days. Consequently, control of delayed phase nausea and anorexia remains an issue (6).

$5 \mathrm{HT}_{3}$ receptor antagonists that are available in Japan include granisetron (Gra), palonosetron (Palo), and ondansetron. Palo, a novel $5 \mathrm{HT}_{3}$ receptor antagonist, has been shown to be more effective in preventing delayed vomiting, compared to other agents $(7,8)$. This is because Palo has a half-life of $40 \mathrm{~h}$, far 
longer than the half-life of the other agents, and its binding affinity for $5 \mathrm{HT}_{3}$ receptors is about 100 times higher.

Few studies have evaluated gastrointestinal adverse events related to the use of antiemetics during chemotherapy for gynecological cancers. In daily practice, symptoms severity and patients' QOL following initial chemotherapy usually determine the choice of antiemetic for the next cycle. We sought to clarify the rates at which nausea and anorexia are controlled, and food intake status, after initial chemotherapy.

\section{Patients and Methods}

Subjects were females who underwent initial chemotherapy for gynecological cancer at Tottori University Hospital between 2008 and 2013 (Table I). The antiemetics used in each case were those recommended by GL2010 for the corresponding emetogenic risk (Table II). Three antiemetics were used for patients who received HEC and two for those who received MEC. Patients in the HEC group received intravenous Palo before chemotherapy administration, as well as the neurokinin-1 (NK-1) receptor antagonist aprepitant (Apr) at doses of $125 \mathrm{mg}$ on day 1 of chemotherapy and $80 \mathrm{mg}$ on days 2 and 3. Dexamethasone (Dex) at $4.0 \mathrm{mg}$ daily was administered at days 2, 3 and 4 post chemotherapy. Patients in the MEC group received intravenous Gra before chemotherapy administration, and $4.0 \mathrm{mg}$ Dex daily at days 2, 3 and 4 post chemotherapy. Palo was used as $5 \mathrm{HT}_{3}$ antagonist for patients administered HEC and Gra for those who received MEC.

We evaluated control rates of nausea and anorexia (\%), calculated as (Grade 0 ) /all $\times 100$, and food intake status in the acute (day 1) and delayed phases (days 2 and 3). Nausea and anorexia severities were graded according to the Common Terminology Criteria for Adverse Events (CTCAE) version 3.0. Food intake status was investigated retrospectively from nursing records, and was graded in terms of whether or not patients had eaten at least half the amount they had eaten at supper on the day before chemotherapy.

\section{Results}

The study subjects included 156 females who underwent initial chemotherapy for gynecological cancer (endometrial cancer in 39 cases, cervical cancer in 39 cases, and ovarian cancer in 78 cases) in Tottori University Hospital between 2008 and 2013 (Table I). HEC regimens including cisplatin were used in 24 cases (doxorubicin + cisplatin in 19 cases, dose-dense paclitaxel + cisplatin in 3 cases, paclitaxel + cisplatin in 1 case, and bleomycin + etoposide + cisplatin in 1 case), and MEC regimens including carboplatin or nedaplatin were used in 132 cases (paclitaxel + carboplatin in 100 cases, camptothecin-11+ nedaplatin in 22 cases, docetaxel + carboplatin in 7 cases, and other regimens in 3 cases). Nausea control rates were $100 \%$ for the HEC group and $97.8 \%$ for the MEC group on day $1,83.3 \%$ and $92.4 \%$ on day 2 , and $75.0 \%$ and $76.5 \%$ on day 3 , respectively (Table III). There was no significant betweengroup difference in the nausea control rates during the acute phase ( $p=0.4558)$; however, in the delayed phase (particularly
Table I. Patient characteristics.

\begin{tabular}{lr}
\hline Years (Median) & $42-78(58)$ \\
Cancer type & 39 \\
Ovarian cancer & 39 \\
Cervical cancer & 78 \\
Endometrial cancer & \\
Emetogenic risk & 24 \\
HEC & 132 \\
MEC & \\
Regimen & \\
HEC & 19 \\
ADM/CDDP & 3 \\
Dose-dense PTX/CDDP & 1 \\
PTX/CDDP & 1 \\
MMC/VP-16/CDDP & \\
MEC & 100 \\
PTX/CBDCA & 22 \\
CPT-11/NDP & 7 \\
DTX/CBDCA & 3 \\
Others & \\
\hline
\end{tabular}

ADM: Doxorubicin; CDDP: cisplatin; PTX: paclitaxel; MMC: bleomycin; VP-16: Etoposide; CBDCA: carboplatin; CPT-11: camptothecin-11; NDP: nedaplatin; DTX: docetaxel.

on day 2), control in the HEC group was significantly inferior to the MEC group $(p<0.0001)$. In the HEC group, nausea control rate was significantly inferior on days 2 and 3 compared to day $1(p=0.0465, p<0.0001)$ (Figure 1). In the MEC group, nausea control rates on days 2 and 3 were both inferior to day $1(p=0.0367, p=0.0088)$, and the rate was worse on day 3 compared to day $2(p=0.0004)$.

There were no significant between-group differences in anorexia control during either the acute or delayed phases (Figure 2). In the HEC group, anorexia control was $100 \%$ on day 1 but declined to $84.6 \%$ on day 2 and $76.9 \%$ on day 3 . However, these differences were non-significant. In the MEC group, the rate of anorexia control was $99.0 \%$ on day 1 , but declined significantly to $93.3 \%$ on day $2(p=0.0306)$ and $83.0 \%$ on day $3(p<0.0001)$.

In the HEC group, $82.6 \%$ of patients ate on day 1 at least half the amount that they ate the day before chemotherapy (Figure 3 ). This declined to $43.4 \%$ on day 2, and $39.1 \%$ on day 3 , representing a significant decline from day 1 $(p=0.006, p=0.0025)$. In the MEC group, $75.3 \%$ consumed at least half of their pre-chemotherapy meal on day $1,60.0 \%$ on day 2 , and $40.0 \%$ on day 3 , again representing a significantly decline (day 1 vs. day $2, p=0.008$; day 2 vs. day 3: $p<0.0001$; day 1 vs. day 3: $p=0.0013$ ).

\section{Discussion}

The adverse events associated with chemotherapy affect patients' QOL and therapeutic compliance (1). In particular, 
Table II. Treatment diagram.

\begin{tabular}{|c|c|c|c|c|c|}
\hline \multirow[b]{2}{*}{ HEC } & \multirow{2}{*}{$\begin{array}{c}\text { Acute phase } \\
\text { Day } 1\end{array}$} & \multicolumn{4}{|c|}{ Delayed phase } \\
\hline & & Day 2 & Day 3 & Day 4 & Day 5 \\
\hline Aprepitant (mg) & 125 & 80 & 80 & & \\
\hline Palonosetron & $*$ & & & & \\
\hline Dexamethasone (mg) & 9.9 & 4 & 4 & 4 & \\
\hline MEC & Day 1 & Day 2 & Day 3 & Day 4 & Day 5 \\
\hline Granisetron & $*$ & & & & \\
\hline Dexamethasone (mg) & $3.3-15.5$ & 4 & 4 & 4 & \\
\hline
\end{tabular}

*Intravenously administered before chemotherapy.

gastrointestinal adverse events diminish the desire for treatment, and may also cause deterioration in the patient's general condition due to poor nutrition and dehydration, potentially leading to thrombosis. Prevention of CINV is essential for continuing chemotherapy, as is appropriate evaluation of each patient's status.

No clear between-group differences were found in nausea control rates during the acute phase. The control rates for delayed nausea were significantly poorer in both groups. Even after combining three antiemetics (Palo, Apr, and Dex), the nausea control rate in the HEC group was only approximately $30 \%-40 \%$, suggesting that a higher dose of Dex or the addition of other antiemetics may be required. To improve nausea and vomiting, other antiemetics, including dopamine receptor antagonists and benzodiazepine anxiolytics, are generally considered as agents with different mechanisms of action (9). For chemotherapy regimens that include cisplatin $\left(>70 \mathrm{mg} / \mathrm{m}^{2}\right)$, the addition of Apr to double combination therapy with first-generation $5 \mathrm{HT}_{3}$ receptor antagonists Gra and Dex has been recommended (10-12). However, even in these studies, the nausea control rate was only around $60 \%$, suggesting that the level of control remained inadequate.

Similarly, the control rate of delayed nausea in the MEC group was around $50 \%-70 \%$, similar to the HEC group with triple combination therapy. Though Gra was used as a 5-HT3 receptor antagonist in this study, its associated control rate was insufficient. MASCC/ESMO 2011 guidelines and ASCO 2011 guidelines recommend the use of combination therapy with Palo and Dex against CINV caused by MEC $(2,4)$. At our hospital, we switched Gra to Paro for MEC, beginning in 2013. The SENRI trial, a Phase III randomized comparative trial of over 400 patients with colorectal cancer who underwent oxaliplatin-based chemotherapy, has shown that the addition of Apr to a 5-HT3 receptor antagonist and Dex was efficacious for control of both overall and delayed vomiting (13). Administration of Apr is clinically beneficial
Table III. Control rates for nausea and loss of appetite.

\begin{tabular}{|c|c|c|c|}
\hline & $\begin{array}{c}\text { HEC } \\
(n=24)\end{array}$ & $\begin{array}{c}\text { MEC } \\
(n=132)\end{array}$ & $p$-Value \\
\hline \multicolumn{4}{|l|}{ Day 1 (acute phase) } \\
\hline None or Grade 1 & 24 & 129 & 0.4558 \\
\hline Grade 2-4 & 0 & 3 & \\
\hline Nausea CR (\%) & 100 & 97.7 & \\
\hline \multicolumn{4}{|l|}{ Day 2 (delayed phase) } \\
\hline None or Grade 1 & 4 & 122 & $<0.0001$ \\
\hline Grade 2-4 & 20 & 10 & \\
\hline Nausea CR (\%) & 83.3 & 92.4 & \\
\hline \multicolumn{4}{|l|}{ Day 3 (delayed phase) } \\
\hline None or Grade 1 & 18 & 101 & 0.8725 \\
\hline Grade 2-4 & 6 & 31 & \\
\hline \multirow[t]{2}{*}{ Nausea CR (\%) } & 75.0 & 76.5 & \\
\hline & $\begin{array}{c}\text { HEC } \\
(n=13)\end{array}$ & $\begin{array}{c}\text { MEC } \\
(n=106)\end{array}$ & $p$-Value \\
\hline \multicolumn{4}{|l|}{ Day 1 (acute phase) } \\
\hline None or Grade 1 & 13 & 105 & 0.7251 \\
\hline Grade 2-4 & 0 & 1 & \\
\hline CR of loss of appetite (\%) & 100 & 99.0 & \\
\hline \multicolumn{4}{|l|}{ Day 2 (delayed phase) } \\
\hline None Grade 1 & 11 & 99 & 0.2584 \\
\hline Grade 2-4 & 2 & 7 & \\
\hline CR of loss of appetite (\%) & 84.6 & 93.3 & \\
\hline \multicolumn{4}{|l|}{ Day 3 (delayed phase) } \\
\hline None or Grade 1 & 10 & 88 & 0.5863 \\
\hline Grade 2-4 & 3 & 18 & \\
\hline CR of loss of appetite (\%) & 76.9 & 83.0 & \\
\hline
\end{tabular}

CR: Control rate.

for patients who are receiving MEC. However, the GL2015 recommendations refer to it only as an option for MEC.

A similar tendency was also observed for anorexia assessments, which correlated with nausea control rate. Prophylactic use or reinforcement of antiemetics should be 

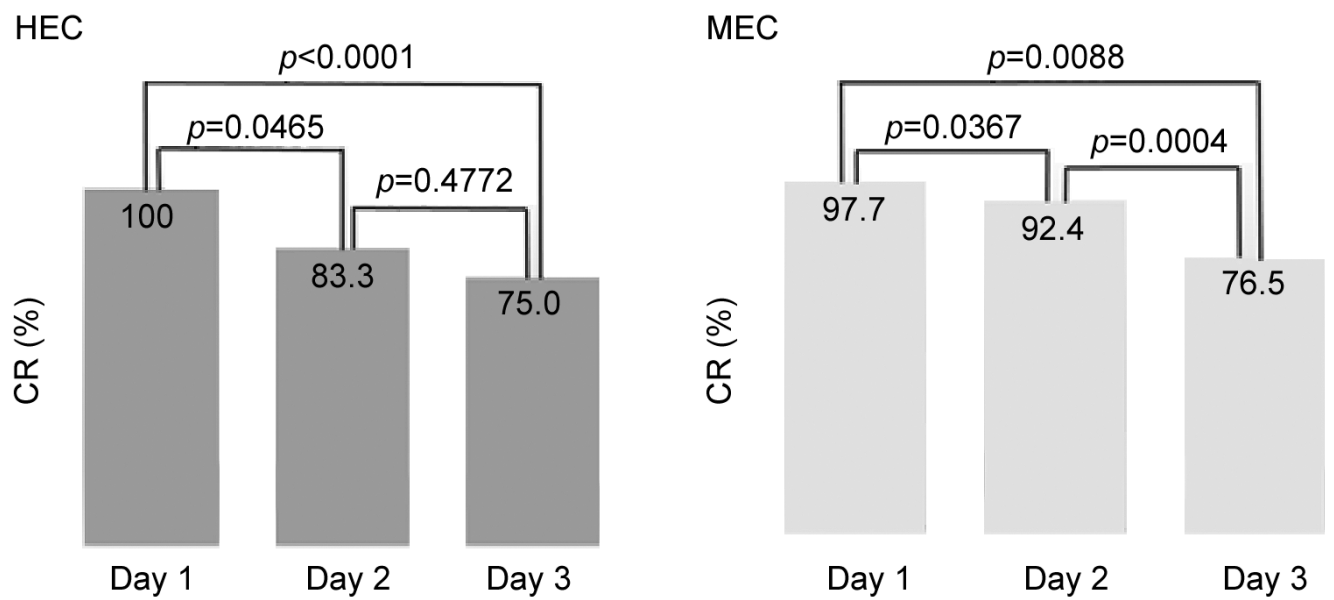

Figure 1. Control rate of nausea.
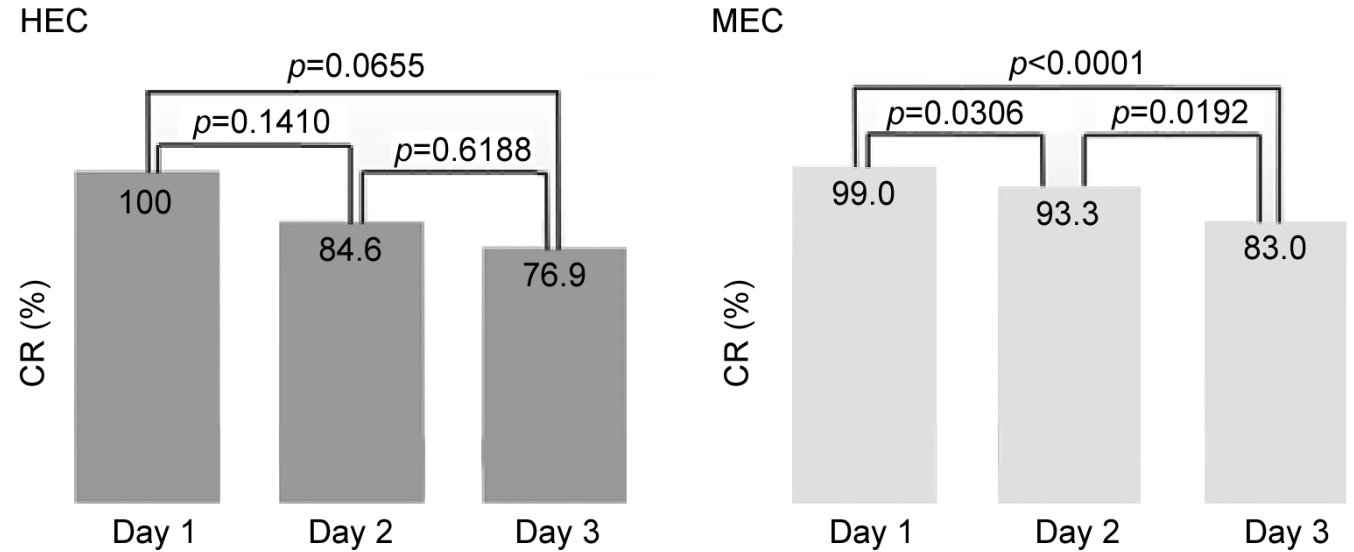

Figure 2. Control rate of loss of appetite.

considered for both HEC and MEC. Although nausea, anorexia, and food intake were well controlled in both groups in the acute phase, they were all poorly controlled in the delayed phase. In the MEC group, the introduction of a novel $5 \mathrm{HT}_{3}$ receptor antagonist and Apr as in the HEC group may improve the control rate and increase food intake. The starting dose of Dex in this study was comparatively low at $4.0 \mathrm{mg}$, and there may be the possibility of improvement by increasing this dose. However, Dex is metabolized by CYP3A4 as Apr which acts as a CYP3A4 inhibitor (14). When Dex and Apr are used together, the dose must be decreased by around $40 \%$. It should also be noted that there are limits to the use of triple antiemetic therapy in patients with, or at risk of diabetes. Despite its frequent use, the risk of diabetes in patients undergoing chemotherapy is not clear. To elucidate the actual risk of diabetes further studies are required.
In June 2017 olanzapine was approved under the Japanese national health insurance program for treatment of CINV. Rudolph et al. have reported that Apr and Olanzapine were equally effective at controlling delayed vomiting (15). In a double-blind randomized trial in which patients were given either olanzapine (10 $\mathrm{mg}$ once daily for 3 days) or metoclopramide (10 $\mathrm{mg}$ three times daily for three days) to treat breakthrough nausea and vomiting after the use of high-risk anticancer agents, olanzapine provided significantly better nausea and vomiting control over the 72$\mathrm{h}$ observation period (16). A systematic review of olanzapine for CINV also found that monotherapy was effective for breakthrough nausea and vomiting (17). The official price of $2.5 \mathrm{mg}$ olanzapine is as low as $138.30 \mathrm{yen}$, compared with the much higher cost of 4945 yen for Apr $125 \mathrm{mg}$. Therefore, this may represent a new treatment 

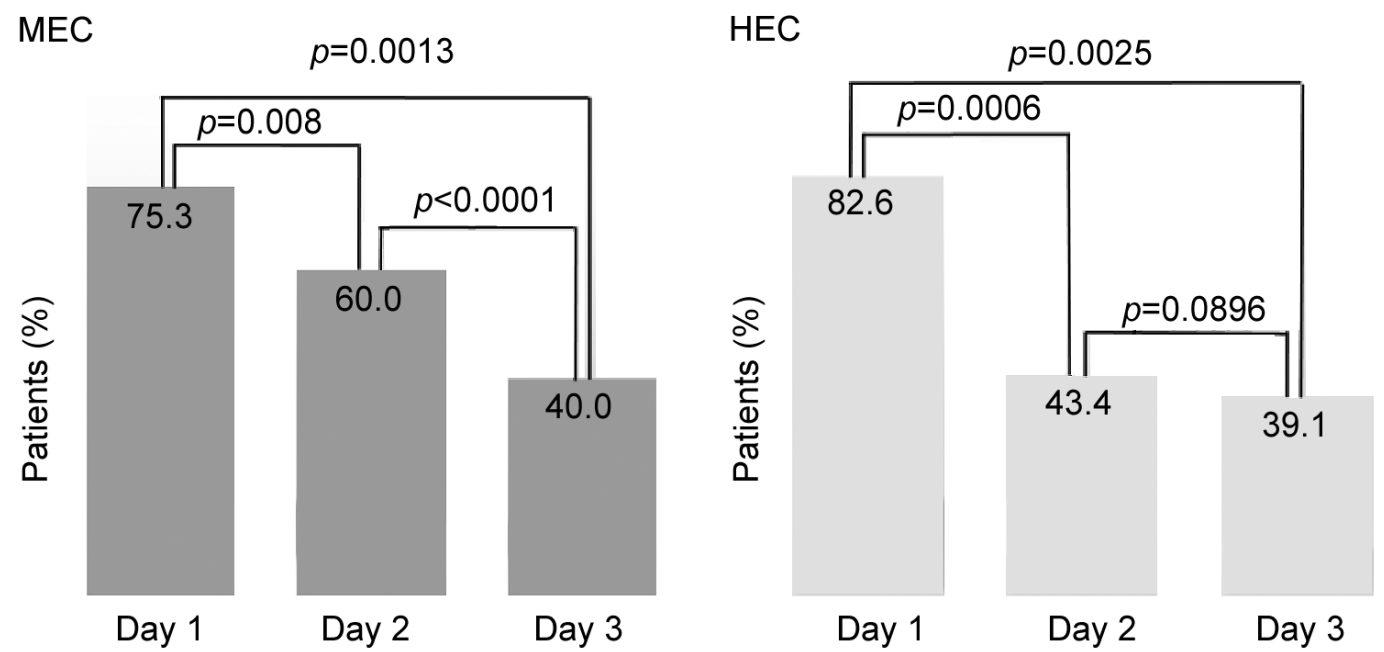

Figure 3. The proportions of patients who ate at least half the amount they ate on the day before chemotherapy.

option that reduces patients' burden. However, additional studies are needed.

This study had some limitations. The first was the short monitoring period. We defined the delayed stage after chemotherapy as days 2 and 3 since the assessments were carried out directly while patients were hospitalized. This may not reflect the actual delayed phase, which can last from more than $24 \mathrm{~h}$ to around 1 week. Second, development of CINV may be affected by psychological factors. Patient-specific characteristics such as hyperemesis gravidarum or pre-existing conditions were not fully taken into account. Third, the dose of Dex was 4 $\mathrm{mg}$ daily for three days starting on day 2 post chemotherapy. In contrast, the recommended dose of GL2015 was $8 \mathrm{mg}$. However, our data suggested that Dex dose was not extremely small in this study. It must also be noted that non-inferiority has been shown for the MEC group who did not receive Dex on days 2 or 3 after Palo administration (18-20).

Because negative impressions formed during initial chemotherapy can affect the patient's ability to tolerate subsequent chemotherapy, antiemetics should be introduced at the start and continue throughout long-term treatment. Our results suggested that current supportive therapies are not sufficiently effective and must be improved. Additional studies are needed to investigate the efficacy of adding Apr in patients who receive MEC.

\section{Conflicts of Interest}

The Authors have no conflicts of interest to declare regarding this study.

\section{Acknowledgements}

This study was supported by enago providing language help, writing assistance or proof reading this article. We would like to express our sincere gratitude to them.

\section{Authors' Contributions}

HK, TO and MS designed the study, and wrote the initial draft of the manuscript. HI, SS and HK contributed to analysis and interpretation of data, and assisted in the preparation of the manuscript. All other authors have contributed to data collection and interpretation, and critically reviewed the manuscript. All authors approved the final version of the manuscript, and agree to be accountable for all aspects of the work in ensuring that questions related to the accuracy or integrity of any part of the work are appropriately investigated and resolved.

\section{References}

1 Italian Group for Antiemetic Research: Dexamethasone alone or in combination with ondansetron for the prevention of delayed nausea and vomiting induced by chemotherapy. N Engl J Med 342(21): 1554-1559, 2000. PMID: 10824073. DOI: 10.1056/NEJ M200005253422102

2 Basch E, Prestrud AA, Hesketh PJ, Kris MG, Feyer PC, Somerfield MR, Chesney M, Clark-Snow RA, Flaherty AM, Freundlich B, Morrow G, Rao KV, Schwartz RN and Lyman GH; American Society of Clinical Oncology: Antiemetics: American Society of Clinical Oncology clinical practice guideline update. J Clin Oncol 29(31): 4189-4198, 2011. PMID: 21947834. DOI: 10.1200/JOP.2011.000397

3 NCCN Clinical Practice Guidelines in Oncology-Antiemesis-ver. 1, 2015. Available at: http://consensocancermamario.com/ guias/NCCN_2015.pdf 
4 MASCC/ESMO Antiemetic Guidelines, 2016. Available at: https://www.mascc.org/assets/Guidelines-Tools/mascc_ antiemetic_guidelines_english_v.1.2.1.pdf

5 Takeuchi H, Saeki T, Aiba K, Tamura K, Aogi K, Eguchi K, Okita K, Kagami Y, Tanaka R, Nakagawa K, Fujii H, Boku N, Wada M, Akechi T, Udagawa Y, Okawa Y, Onozawa Y, Sasaki H, Shima Y, Shimoyama N, Takeda M, Nishidate, Yamamoto A, Ikeda $\mathrm{T}$ and Hirata K: Japanese Society of Clinical Oncology clinical practice guidelines 2010 for antiemesis in oncology: executive summary. Int J Clin Oncol 21(1): 1-12, 2016. PMID: 26081252. DOI: $10.1007 / \mathrm{s} 10147-015-0852-1$

6 Kaizer L, Warr D, Hoskins P, Latreille J, Lofters W, Yau J, Palmer M, Zee B, Levy M and Pater J: Effect of schedule and maintenance on the antiemetic efficacy of ondansetron combined with dexamethasone in acute and delayed nausea and emesis in patients receiving moderately emetogenic chemotherapy: A phase III trial by the National Cancer Institute of Canada Clinical Trial Group. J Clin Oncol 12: 1050-1057, 1994. PMID: 8164029. DOI: 10.1200/JCO.1994.12.5.1050

7 Hashimoto H, Yamanaka T, Shimada Y, Arata K, Matsui R, Goto K, Takiguchi T, Ohyanagi F, Kogure Y, Nogami N, Nakao M, Takeda K, Azuma K, Nagase S, Hayashi T, Fujiwara K, Shimada T, Seki N, Suzuki $\mathrm{K}$ and Yamamoto $\mathrm{N}$ : Palonosetron (PALO) versus granisetron (GRA) in the triplet regimen with dexamethasone (DEX) and aprepitant (APR) for preventing chemotherapy-induced nausea and vomiting (CINV) in patients (pts) receiving highly emetogenic chemotherapy (HEC) with cisplatin (CDDP): A randomized, doubleblind, phase III trial. J Clin Oncol 31: abstr 9621, 2013.

8 Matsumoto K, Takahashi M, Sato K, Takano T, Ryushima Y, Doi K, Aogi M, Fujiwara K, Tamura K, Hosoda M, Tokunaga S, Makiyama A, Miyamoto K, Hozumi Y, Yanagihara K, Imamura C, Chiba Y, Nakamura S and Saeki T: Palonosetron or granisetron for prevention of CINV in patients with breast cancer receiving dexamethasone and fosaprepitant following anthracycline plus cyclophosphamide (AC) regimen. J Clin Oncol 33: abstr 9598, 2015.

9 Glare P, Pereira G, Kristjanson LJ, Stockler M and Tattersall M: Systematic review of the efficacy of antiemetics in the treatment of nausea in patients with far-advanced cancer. Support Care Cancer 12(6): 432-440, 2004. PMID: 15108099. DOI: 10.1007/ s00520-004-0629-y

10 Jones JM, Qin R, Bardia A, Linquist B, Wolf S and Loprinzi CL: Antiemetics for chemotherapy-induced nausea and vomiting occurring despite prophylactic antiemetic therapy. J Palliat Med 14(7): 810-814, 2011. PMID: 21554125. DOI: 10.1089/jpm. 2011.0058

11 Hesketh PJ, Grunberg SM, Gralla RJ, Warr DG, Roila F, de Wit R, Chawla SP, Carides AD, Ianus J, Elmer ME, Evans JK, Beck K, Reines S and Horgan KJ; Aprepitant Protocol 052 Study Group: The oral neurokinin-1 antagonist aprepitant for the prevention of chemotherapy-induced nausea and vomiting: a multinational, randomized, double-blind, placebo-controlled trial in patients receiving high-dose cisplatin - the Aprepitant Protocol 052 Study Group. J Clin Oncol 21(22): 4112-4119, 2003. PMID: 14559886. DOI: 10.1200/JCO.2003.01.095

12 de Wit R, Herrstedt J, Rapoport B, Carides AD, Guoguang-Ma J, Elmer M, Schmidt C, Evans JK and Horgan KJ: The oral NK(1) antagonist, aprepitant, given with standard antiemetics provides protection against nausea and vomiting over multiple cycles of cisplatin-based chemotherapy: a combined analysis of two randomised, placebo-controlled phase III clinical trials. Eur J Cancer 40(3): 403-410, 2004. PMID: 14746859. DOI: https:// doi.org/10.1016/j.ejca.2003.08.028

13 Nishimura J, Satoh T, Fukunaga M, Takemoto H, Nakata K, Ide Y, Fukuzaki T, Kudo T, Miyake Y, Yasui M, Morita S, Sakai D, Uemura M, Hata T, Takemasa I, Mizushima T, Ohno Y, Yamamoto H, Sekimoto M, Nezu R, Doki Y, Mori M and Multi-center Clinical Study Group of Osaka, Colorectal Cancer Treatment Group (MCSGO): Combination antiemetic therapy with aprepitant/fosaprepitant in patients with colorectal cancer receiving oxaliplatin-based chemotherapy (SENRI trial): A multicentre, randomised, controlled phase 3 trial. Eur J Cancer 51(10): 12741282, 2015. PMID: 25922233. DOI: 10.1016/ j.ejca.2015.03.024

14 McCrea JB, Majumdar AK, Goldberg MR, Iwamoto M, Gargano C, Panebianco DL, Hesney M, Lines CR, Petty KJ, Deutsch PJ, Murphy MG, Gottesdiener KM, Goldwater DR and Blum RA: Effects of the neurokinin1 receptor antagonist aprepitant on the pharmacokinetics of dexamethasone and methylprednisolone. Clin Pharmacol Ther 74(1): 17-24, 2003. PMID: 12844131. DOI: $10.1016 / \mathrm{S} 0009-9236(03) 00066-3$

15 Navari RM Qin R, Rubby KJ, Liu H, Powell SF, Bajaj M, Dietrich L, Biggs D, Lafky JM and Loprinzi CL: Olanzapine for the prevention of chemotherapy-induced nausea and vomiting. N Engl J Med 375: 134-142, 2016. PMID: 27410922. DOI: 10.1056/NEJMoa1515725

16 Navari RM, Nagy CK and Gray SE: The use of olanzapine versus metoclopramide for the treatment of breakthrough chemotherapyinduced nausea and vomiting in patients receiving highly emetogenic chemotherapy. Support Care Cancer 21(6): 16551663, 2013. PMID: 23314603. DOI: 10.1007/s00520-012-1710-6

17 Hocking CM and Kichenadasse G: Olanzapine for chemotherapyinduced nausea and vomiting: a systematic review. Support Care Cancer 22: 114, 2014. PMID: 24522741. DOI: 10.1007/s00520014-2138-y

18 Aapro M, Fabi A, Nolè F, Medici M, Steger G, Bachmann C, Roncoroni S and Roila F: Double-blind, randomised, controlled study of the efficacy and tolerability of palonosetron plus dexamethasone for 1 day with or without dexamethasone on days 2 and 3 in the prevention of nausea and vomiting induced by moderately emetogenic chemotherapy. Ann Oncol 21(5): 10831088, 2010. PMID: 20080830. DOI: 10.1093/annonc/ mdp584

19 Celio L, Frustaci S, Denaro A, Buonadonna A, Ardizzoia A, Piazza E, Fabi A, Capobianco AM, Isa L, Cavanna L, Bertolini A, Bichisao E, Bajetta E and Italian Trials in Medical Oncology Group: Palonosetron in combination with 1-day versus 3-day dexamethasone for prevention of nausea and vomiting following moderately emetogenic chemotherapy: a randomized, multicenter, phase III trial. Support Care Cancer 19: 1217-1225, 2011. PMID: 20574663. DOI: 10.1007/s00520-010-0941-7

20 Komatsu Y, Okita K, Yuki S, Furuhata T, Fukushima H, Masuko H, Kawamoto Y, Isobe H, Miyagishima T, Sasaki K, Nakamura M, Ohsaki Y, Nakajima J, Tateyama M, Eto K, Minami S, Yokoyama R, Iwanaga I, Shibuya H, Kudo M, Oba K and Takahashi Y: Openlabel, randomized, comparative, phase III study on effects of reducing steroid use in combination with Palonosetron. Cancer Sci 106(7): 891-895, 2015. PMID: 25872578. DOI: 10.1111/cas.12675

Received May 23, 2019

Revised June 19, 2019

Accepted June 20, 2019 